(c) Center for Health Disparities Research, School of Public Health, University of Nevada, Las Vegas

2012

\title{
Racial Disparities in Pain Management in Primary Care
}

Miriam Ezenwa , moezenwa@uic.edu

Follow this and additional works at: https://digitalscholarship.unlv.edu/jhdrp

Part of the Nursing Commons, Public Health Commons, and the Race and Ethnicity Commons

\section{Recommended Citation}

Ezenwa, Miriam (2012) "Racial Disparities in Pain Management in Primary Care," Journal of Health Disparities Research and Practice: Vol. 5: Iss. 3, Article 1.

Available at: https://digitalscholarship.unlv.edu/jhdrp/vol5/iss3/1

This Article is protected by copyright and/or related rights. It has been brought to you by Digital Scholarship@UNLV with permission from the rights-holder(s). You are free to use this Article in any way that is permitted by the copyright and related rights legislation that applies to your use. For other uses you need to obtain permission from the rights-holder(s) directly, unless additional rights are indicated by a Creative Commons license in the record and/ or on the work itself.

This Article has been accepted for inclusion in Journal of Health Disparities Research and Practice by an authorized administrator of Digital Scholarship@UNLV. For more information, please contact digitalscholarship@unlv.edu. 


\title{
Racial Disparities in Pain Management in Primary Care
}

\begin{abstract}
This descriptive, cross-sectional, secondary data analysis was conducted to examine racial disparities in pain management of primary care patients with chronic nonmalignant pain using chronic opioid therapy. Data from 891 patients, including 201 African Americans and 691 Caucasians were used to test an explanatory model for these disparities. We predicted that: (1) African American patients would report worse pain management and poor quality of life (QOL) than Caucasians; (2) the association between race and pain management would be mediated by perceived discrimination relating to hopelessness; and (3) poor pain management would negatively affect QOL. Results revealed significant differences between African Americans and Caucasians on pain management and QOL, with African Americans faring worse. The proposed mediational model, which included race, perceived discrimination, hopelessness, and pain management was supported: (1) African Americans compared to Caucasians had higher perceived discrimination, (2) perceived discrimination was positively associated with hopelessness, and (3) higher hopelessness was associated with worse pain management. Further, pain management predicted QOL. This is the first study in which an explanatory model for the racial disparities in pain management of primary care patients with chronic nonmalignant pain was examined. Perceived discrimination and hopelessness were implicated as explanatory factors for the disparities.
\end{abstract}

\section{Keywords}

African Americans; Chronic nonmalignant pain; Chronic pain; Discrimination in medical care; Model of racial disparities; Pain - Treatment; Pain management; Perceived discrimination; Racial and ethnic minorities; Social status - Health aspects

\section{Cover Page Footnote}

Funding Support: The Funding for this work was made possible by the National Institute of Nursing Research-National Research Service Award (NINR-NRSA) grant: 1F31NR010820 (Principal Investigation: Miriam O. Ezenwa, PhD, RN) and R01DA013686 (Principal Investigator: Michael Fleming, MD, MPH). Acknowledgements: The first author thanks Sandra E. Ward, PhD, RN, FAAN, the Chair of her Dissertation Committee and Ronald C. Serlin, PhD, the Secondary Advisor for their conceptual contributions in their respective substantive areas. The first author also thanks Diana J. Wilkie, PhD, RN, FAAN, her research Faculty Mentor at the University of Illinois at Chicago and Patrick J. McGrath, OC, PhD, FRSC, FCAHS for their contribution with manuscript revisions. 


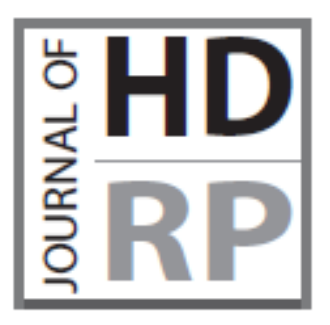

Journal of Health Disparities Research and Practice

Volume 5, Issue 3, Fall 2012, pp. 12-26

(C) 2011 Center for Health Disparities Research

School of Community Health Sciences

University of Nevada, Las Vegas

\section{Racial Disparities in Pain Management in Primary Care}

Miriam O. Ezenwa, PhD, RN, University of Illinois at Chicago

Michael F. Fleming, MD, MPH, Northwestern University

\section{ABSTRACT}

This descriptive, cross-sectional, secondary data analysis was conducted to examine racial disparities in pain management of primary care patients with chronic nonmalignant pain using chronic opioid therapy. Data from 891 patients, including 201 African Americans and 691 Caucasians were used to test an explanatory model for these disparities. We predicted that: (1) African American patients would report worse pain management and poor quality of life (QOL) than Caucasians; (2) the association between race and pain management would be mediated by perceived discrimination relating to hopelessness; and (3) poor pain management would negatively affect QOL. Results revealed significant differences between African Americans and Caucasians on pain management and QOL, with African Americans faring worse. The proposed mediational model, which included race, perceived discrimination, hopelessness, and pain management was supported: (1) African Americans compared to Caucasians had higher perceived discrimination, (2) perceived discrimination was positively associated with hopelessness, and (3) higher hopelessness was associated with worse pain management. Further, pain management predicted QOL. This is the first study in which an explanatory model for the racial disparities in pain management of primary care patients with chronic nonmalignant pain was examined. Perceived discrimination and hopelessness were implicated as explanatory factors for the disparities.

Keywords: Pain Management, chronic nonmalignant pain, model of racial disparities, racial and ethnic minorities, perceived discrimination 


\section{INTRODUCTION}

There are racial disparities in pain management in the United States. Systematic literature reviews revealed that African Americans are more at risk than Caucasians for experiencing under-treatment of pain (Cintron \& Morrison, 2006; Ezenwa, Ameringer, Ward, \& Serlin, 2006; Meghani, Byun, \& Gallagher, 2012). There are several important gaps in our understanding of disparities in pain management, including a lack of attention to disparities in pain management in primary care settings. Investigators of only one study examined racial disparities in the pain management of primary care patients with chronic nonmalignant pain (Chen et al., 2005). Chen and colleagues found that African Americans reported worse pain scores than Caucasians (Chen, et al., 2005). No study, however, provides insights about explanatory models that would further our understanding of disparities. The purpose of this study was to examine whether there are racial disparities in pain management of primary care patients with chronic nonmalignant pain using chronic opioid therapy and to test an empirical model that proposes an explanation for these disparities.

The proposed explanatory model, which addresses relationships among perceived discrimination, hopelessness, and racial disparities in proximal [pain management] and distal [quality of life] pain outcomes, is based on a synthesis of research on pain treatment, perceived discrimination, and hopelessness and their impact on health outcomes. We define everyday perceived discrimination as chronic, routine, and relatively minor experiences of unfair treatment (Williams, Yu, Jackson, \& Anderson, 1997). Hopelessness is defined as a negative expectation about one's present and future life (Everson, Kaplan, Goldberg, Salonen, \& Salonen, 1997). These concepts have been examined in other healthcare areas. For example, African Americans who reported perceived discrimination are more likely to have higher diastolic blood pressure than their Caucasian counterparts (Lewis et al., 2009). Further, African Americans who reported feelings of hopelessness are more at risk for mortality than their Caucasian counterparts (Fiscella \& Franks, 1997). Investigators have not examined the effects of perceived discrimination and hopelessness on pain management disparities, especially not in primary care patients with chronic nonmalignant pain who were using chronic opioid therapy.

However, the available research evidence supports several assertions. Investigators have found that the experience of racial discrimination is more common among African Americans than Caucasians (Feagin \& Feagin, 1991; Krieger, 1990). For example, 43\% of African Americans compared to $4 \%$ of Caucasians report experiencing discrimination regularly (Ren, Amick, \& Williams, 1999). Others have reported that hopelessness adversely affects health and that there are differential racial effects in which African Americans suffer the most compared to Caucasians (Anda et al., 1993; Fiscella \& Franks, 1997). For instance, 40\% of African Americans report having a hopeless outlook compared to $28 \%$ of Caucasians (Fiscella \& Franks, 1997). The experience of perceived discrimination may evoke fear, self-doubt, and anger (Krieger, 1990). Others have reported that patients who blamed discrimination for their failures also reported greater hopelessness (Rusch et al., 2009). In this study, we focused on the effect of everyday perceived discrimination on hopelessness. Perceived discrimination, which is related to feelings of hopelessness, could, at least in part, explain racial disparities in pain management. Finally, investigators have suggested that quality of life (QOL) issues are huge concerns in patients with chronic nonmalignant pain. Patients with chronic nonmalignant pain usually report lower quality of life compared to the general population (Dillie, Fleming, Mundt, \& French, 2008; Fredheim et al., 2008; Tuzun, 2007). 
Using these research findings to better understand the relationship among these variables in primary care patients with chronic nonmalignant pain, we proposed that: (1) African American patients will report worse pain management and poorer QOL than Caucasians; (2) the association between race and pain management will be mediated by perceived discrimination relating to hopelessness; and (3) poor pain management will negatively affect QOL. Unfortunately, previous investigators have not explored the influence of perceived discrimination on hopelessness and pain management in primary care patients with chronic nonmalignant pain who were using chronic opioid therapy. The specific study aims were to: (1) examine the relationship between race and proximal (pain management) and distal (QOL) pain outcomes, (2) test whether perceived discrimination relating to hopelessness mediates the relationship between race and pain management, and (3) test whether pain management influences QOL (See Figure 1).

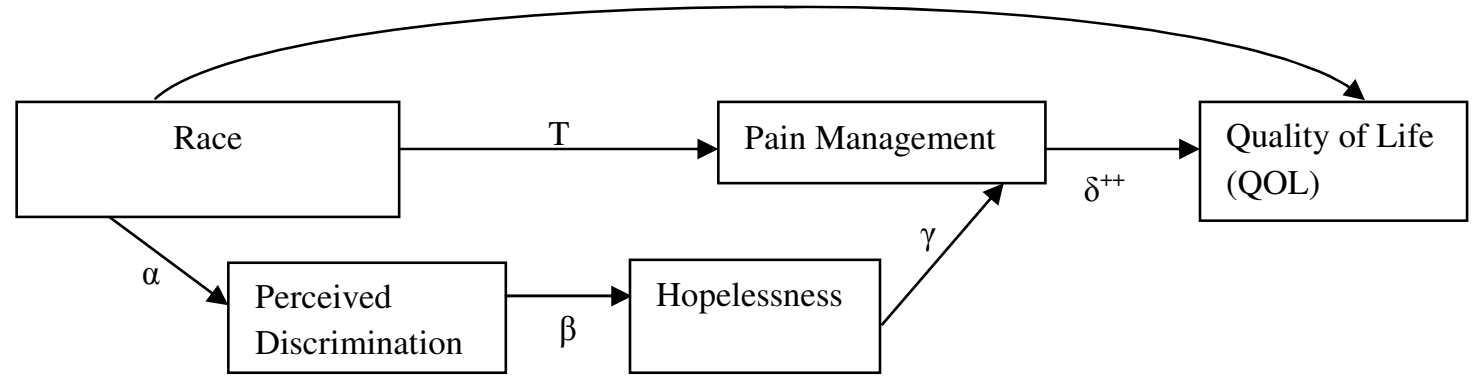

Figure 1. Conceptual Model of Racial Disparities in Pain Management

Note. $\alpha=$ race - perceived discrimination path; $\beta=$ perceived discrimination - mediator (Hopelessness) path; $\gamma=$ mediator - pain management path; and $\delta=$ pain management - quality of life path; ++ A separate aim. Not part of the mediator factor.

\section{METHODS}

\section{Design}

This study was a descriptive, cross-sectional, secondary analysis of an existing dataset. Data were collected from primary care patients with chronic nonmalignant pain in a single state in the Midwestern United States.

\section{Parent study}

Human Subjects Committees in each of six participating healthcare systems approved the parent study. Eligibility criteria were: being 18 years or older, having chronic nonmalignant pain that had lasted for at least three months, and being treated with opioid therapy. Note that the perceived discrimination questionnaire was added after the study began. The first group of recruited participants $(\mathrm{N}=93)$ did not complete this questionnaire. More details about the methods of the parent study are reported elsewhere (Fleming, Balousek, Klessig, Mundt, \& Brown, 2007).

\section{Subjects and Procedures}

Of the 1009 participants in the original dataset, 914 (90.6\%) completed the perceived discrimination questionnaire. We had a total of 892 participants when the inclusion criteria of being African American or Caucasian and having completed the perceived discrimination questionnaire were applied to the dataset. The mean (SD) age of participants was 49.07 (10.54) years; ranged from 18-81 years. The majority were Caucasian $(n=691,77.5 \%)$ and female $(n=$ $624,70.0 \%$ ). Other patients' sociodemographic characteristics are provided in Table 1. 
Table 1. Demographic and Clinical Variables of all Participants and broken down by African Americans versus Caucasians (N=892)

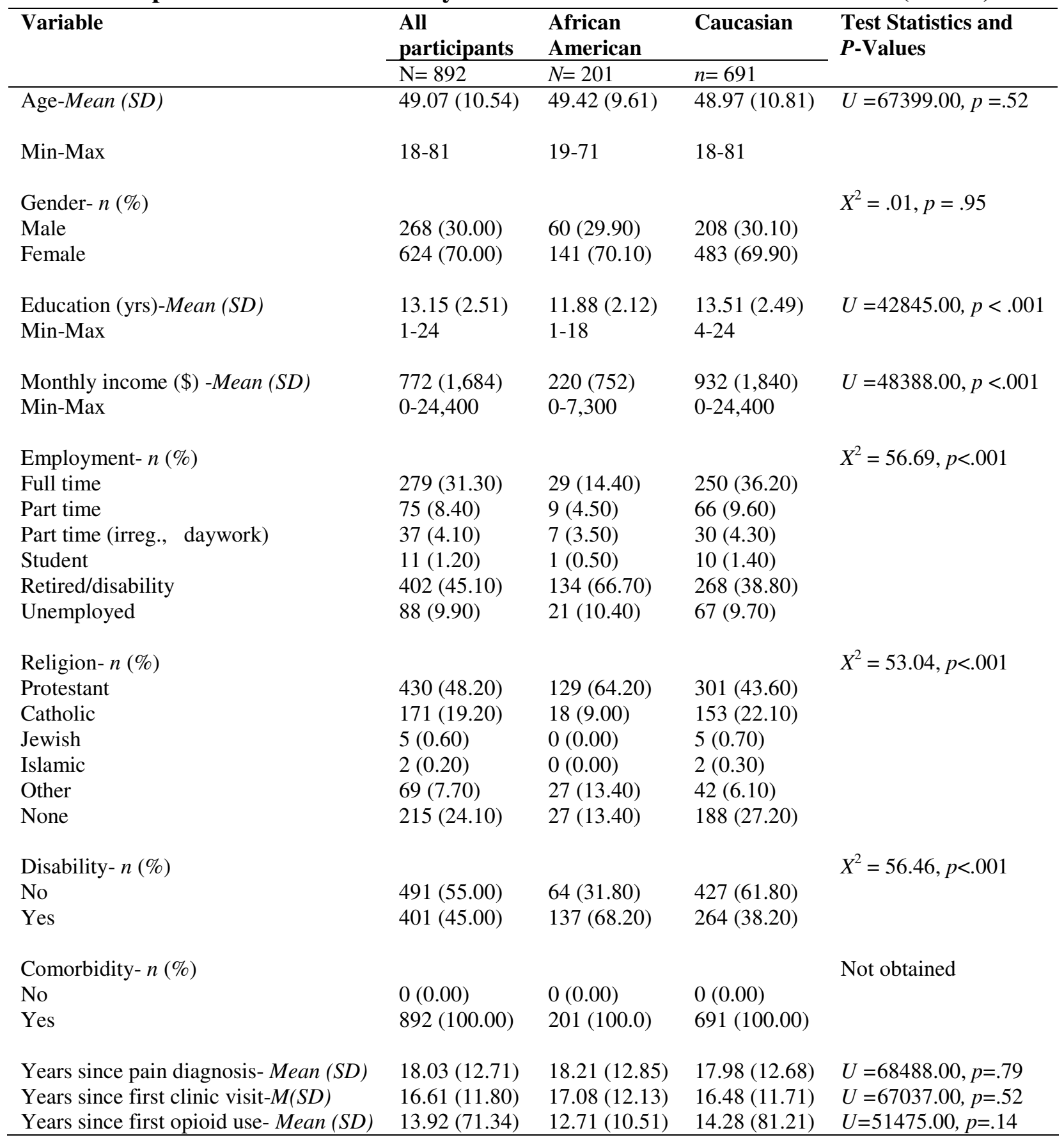

\section{MEASURES}

We used two outcome measures. The Pain Management Composite Score was created in two steps using pain severity (Cleeland \& Ryan, 1994; Tan, Jensen, Thornby, \& Shanti, 2004), opioid dose used, and satisfaction with pain treatment (Ho \& LaFleur, 2004) according to the procedure described by Marascuilo and Levin (Marascuilo \& Levin, 1983). Scholars recommend that when the main outcome scores are equally important, as is the case with these 
three concepts that make up the pain management construct, they should be replaced with a single outcome summary score, such as pain management composite score (Schouten, 2000). Using this approach, we preserve degrees of freedom, conserve sample size, and improve the power of statistical tests (Schouten, 2000). Further, these measures have demonstrated adequate reliability alphas in previous studies (Cleeland \& Ryan, 1994; Tan, et al., 2004). In the current study, the reliability alpha of pain severity scale was .76, and for the satisfaction scale the alpha was .86. Opioid dose used was computed by converting all opioid medications to morphine equivalents per day and this was the value used in data analyses. For example, a larger opioid dose used for moderate to severe pain intensity indicated better pain management.

To create the pain management composite score, first, Z-scores of pain severity, opioid dose used, and satisfaction with pain treatment were created in order to standardize them to the same scale with a mean of 0 and a standard deviation of 1 . Second, the Z-scores of opioid dose used and satisfaction with pain treatment were added together, and the Z-score of pain severity was then subtracted. The Z-scores for opioid dose used and satisfaction with pain treatment were added because higher scores on these variables are desirable. The Z-score for pain severity was subtracted because higher score on this variable is not desirable. A higher pain management composite score reflects better pain management. The pain management composite score demonstrated its validity in this sample. The score correlated in the predicted direction with quality of life [SHARP $X^{2}(1, N=888)=54.96, p<.001$ ], showing the validity of the score.

Quality of life was measured using the RAND-36 Health Survey 1.0 (a modified SF-36 Health Survey), a multi-item measure of health-related QOL in eight domains (Goertz, 1994). Scores ranged from 0 (low) to 100 (high), with lower scores indicating poor QOL. Items were averaged to form 8 subscales. The internal consistency of the eight subscales in a previous study ranged from .73 to .96 (Brazier et al., 1992) and in this sample ranged from .72 to .91. A QOL composite score was created by converting scores to Z-scores. The reliability alpha for the QOL composite score in this sample was .85.

Two mediating measures were used: Everyday perceived discrimination and hopelessness. Perceived discrimination was measured with 9 items (Williams, et al., 1997). Response options ranged from 1 (Never) to 5 (Very often). An overall perceived discrimination score was computed by taking the mean of these items. Higher scores indicated greater perceived discrimination. This scale has a good reliability $(\alpha)$ of .88 (Williams, et al., 1997) and has been validated in both younger and older populations (Barnes et al., 2004; Finch, Kolody, \& Vega, 2000; Williams, et al., 1997) and in this sample the reliability alpha was .89. Hopelessness was measured with two items, which were part of the Pain Patient Profile (P-3) that measured emotional functioning in patients with pain (Willoughby, Hailey, \& Wheeler, 1999). Each item is followed by three general statements about expectations about one's present and future life, indicating: (1) low, (2) moderate, and (3) high hopelessness. A total hopelessness score was calculated by taking the mean of these two items. Higher scores indicated higher hopelessness. The reliability alpha in this sample was .73. 
17 Racial Disparities in Pain Management in Primary Care - Ezenwa, et al.

\begin{tabular}{|c|c|c|c|c|}
\hline Variable and Race & Mean (SD) & Median & Mode & $\begin{array}{l}\text { Min-Max } \\
\text { (Obtained) }\end{array}$ \\
\hline Perceived discrimination & & & & \\
\hline African Americans & $2.01(0.81)$ & 1.89 & 1.00 & $1-5$ \\
\hline Caucasians & $1.77(0.65)$ & 1.67 & 1.00 & $1-4.78$ \\
\hline Hopelessness & & & & \\
\hline African Americans & $1.52(0.63)$ & 1.50 & 1.00 & $1-3$ \\
\hline Caucasians & $1.50(0.59)$ & 1.00 & 1.00 & $1-3$ \\
\hline Pain Management & & & & \\
\hline African Americans & $-.78(1.78)$ & -.94 & -2.43 & $-5.34-5.57$ \\
\hline Caucasians & $.22(1.74)$ & .21 & .08 & $-4.70-7.15$ \\
\hline Quality of Life & & & & \\
\hline African Americans & $-2.12(4.88)$ & -2.30 & -11.74 & $-11.74-12.42$ \\
\hline Caucasians & $.63(5.66)$ & .21 & -12.57 & $-12.57-16.26$ \\
\hline
\end{tabular}

\section{ANALYSIS}

SPSS for Windows Version 16.0 (2007; SPSS Inc., Chicago, IL) was used for all analyses. Descriptive statistics were computed to describe the demographic and clinical variables of the sample. Mann-Whitney $U$-tests were used to compare African Americans and Caucasians on ordered variables, whereas the Fisher exact test and exact p-values were used to compare African Americans and Caucasians on unordered categorical variables. The Serlin-Harwell Aligned-Ranked Procedure (SHARP), a non-parametric regression analysis technique appropriate for non-normally distributed data (Serlin \& Harwell, 2004), was used to test for differences between the medians of African Americans and Caucasians on pain outcomes: pain management composite score and QOL composite score (Serlin \& Harwell, 2004). Each analysis was allotted a Type I error rate of 0.05 .

Further, a series of multiple regression analyses were used to test for mediation based on the joint significance test approach (MacKinnon, Lockwood, Hoffman, West, \& Sheets, 2002). The joint significance approach to mediation is the best of the all the causal steps approaches because it has more statistical power and the lowest Type I error rate (Krause et al., 2010). Table 3 lists the variables tested in the model. Evidence of mediation effects was deduced when tests of the race - perceived discrimination path $(\alpha)$, perceived discrimination - hopelessness path $(\beta)$, and hopelessness - pain management path $(\gamma)$ were all significant. To test the $\alpha$ path, age, income, education, and disability were used as covariates, race and gender, were used as the independent variables, and perceived discrimination was the dependent variable. In testing the $\beta$ path, the pooled within-group relationship between perceived discrimination and hopelessness was evaluated, controlling for covariates, with race and gender as independent variables. To test the $\gamma$ path, the pooled within-group relationship between hopelessness and pain management was examined, controlling for perceived discrimination and covariates, with race, gender as independent variables. Further, the pain management - QOL path $(\delta)$ was examined. In testing the $\delta$ path, the pooled within-group relationship between pain management and QOL was examined using the pain management composite score as the independent variable and QOL composite score as the dependent variable, controlling for perceived discrimination, hopelessness, race, gender, and covariates- age, income, education, and disability. Paths were tested using the SHARP procedure. Each analysis was assigned a Type I error rate of 0.05 . 
Table 3. Variables Included in Testing the Model of Racial Disparities in Pain Management

\begin{tabular}{|c|c|c|c|}
\hline Paths & Covariates & $\begin{array}{l}\text { Independent } \\
\text { variable(s) }\end{array}$ & $\begin{array}{l}\text { Dependent } \\
\text { variable }\end{array}$ \\
\hline $\begin{array}{l}\text { Race-perceived } \\
\text { discrimination }(\alpha)\end{array}$ & $\begin{array}{l}\text { Age } \\
\text { Income } \\
\text { Education } \\
\text { Disability }\end{array}$ & $\begin{array}{l}\text { Race** } \\
\text { Gender }\end{array}$ & $\begin{array}{l}\text { Perceived } \\
\text { discrimination }\end{array}$ \\
\hline $\begin{array}{l}\text { Perceived discrimination- } \\
\text { mediator (Hopelessness) } \\
\text { path }(\beta)\end{array}$ & $\begin{array}{l}\text { Age } \\
\text { Income } \\
\text { Education } \\
\text { Disability }\end{array}$ & $\begin{array}{l}\text { Race } \\
\text { Gender } \\
\text { Perceived } \\
\text { discrimination** }\end{array}$ & Hopelessness \\
\hline $\begin{array}{l}\text { Mediator - pain } \\
\text { management path }(\gamma)\end{array}$ & $\begin{array}{l}\text { Age } \\
\text { Income } \\
\text { Education } \\
\text { Disability }\end{array}$ & $\begin{array}{l}\text { Race } \\
\text { Gender } \\
\text { Perceived discrimination } \\
\text { Hopelessness** }\end{array}$ & Pain management \\
\hline $\begin{array}{l}\text { Pain management - quality } \\
\text { of life path }(\delta)\end{array}$ & $\begin{array}{l}\text { Age } \\
\text { Income } \\
\text { Education } \\
\text { Disability }\end{array}$ & $\begin{array}{l}\text { Race } \\
\text { Gender } \\
\text { Perceived discrimination } \\
\text { Hopelessness } \\
\text { Pain Management** }\end{array}$ & Quality of life \\
\hline
\end{tabular}

Note. ** Independent variable(s) being tested in each path.

\section{RESULTS}

Comparison of African Americans and Caucasians on Demographic and Clinical Variables

African Americans and Caucasians were compared on demographic and clinical variables (Table 1). We found that African Americans earned less income than Caucasians Mann-Whitney $U=48388.00, n_{1}=691, n_{2}=201, p<.001, \alpha=.35$ ( $\alpha$ is a measure of stochastic superiority that indicates the probability that an observation from one population will exceed an observation from another population; here, $\alpha=.35$ indicates that the probability is .65 that an African American will have lower income than a Caucasian), and had fewer years of education than Caucasians, Mann-Whitney $U=42845.00, n_{1}=691, n_{2}=201, p<.001, \alpha=.31$ (probability is .69 that an African Americans will have fewer years of education). There was a statistically significant difference between African Americans and Caucasians regarding employment $X^{2}(1, N$ $=892)=56.69, p<.001, \varphi=.25$. Greater proportions of Caucasians were working a full-time job $(36.2 \%)$ or part-time job (9.6\%) than the proportions of African Americans working a fulltime job (14.4\%) or part-time job (4.5\%). Greater proportions of African Americans were retired/disabled $(66.7 \%)$ or unemployed $(10.4 \%)$ than the proportions of Caucasians who were retired/disabled $(38.8 \%)$ or unemployed $(9.7 \%)$. There were no significant differences between African Americans and Caucasian on median age and gender.

Further, African Americans were significantly more likely to report chronic pain-related disability than Caucasians $\left[X^{2}(1, N=892)=56.46, p<.001, \varphi=.25\right]$. There were no significant differences between African Americans and Caucasians on years since pain diagnosis, years since first visit to pain clinic, and years since first opioid use.

Relationship between Race and Pain Outcomes

There was a statistically significant difference between the medians of African Americans and Caucasians on pain management composite scores $\operatorname{SHARP}\left[X^{2}(1, N=890)=\right.$ 
38.94, $p<.001$, Squared Partial Correlation Coefficient $=.04]$ controlling for age, gender, income, education, and disability. The direction of the slope indicates that African Americans reported worse pain management scores than Caucasians. Further, race was a significant predictor of QOL SHARP $\left[X^{2}(1, N=889)=10.76, p<.001\right.$, Squared Partial Correlation Coefficient $=.02]$ controlling for age, income, education, disability, and gender. The race slope indicated that African Americans reported lower QOL scores than Caucasians.

\section{Test of Mediation Model}

Tables 2 and 3 provide the description of variables included for testing each path in the model. The race-perceived discrimination path $(\alpha)$ was significant, which indicated that race was a significant predictor of perceived discrimination $\operatorname{SHARP}\left[X^{2}(1, N=891)=5.57, p=.02\right.$, Squared Partial Correlation Coefficient $=.01]$. The slope for race indicated that African Americans reported more perceived discrimination than Caucasians. The perceived discrimination - hopelessness path $(\beta)$ was significant, demonstrating that perceived discrimination was a significant predictor of hopelessness $\operatorname{SHARP}\left[X^{2}(1, N=890)=39.87, p<\right.$ .001 , Squared Partial Correlation Coefficient $=.05]$. The slope for perceived discrimination indicated that higher scores on perceived discrimination were associated with higher hopelessness scores. The hopelessness - pain management path $(\gamma)$ was significant, which shows that hopelessness was a significant predictor of pain management $\operatorname{SHARP}\left[X^{2}(1, N=890)=\right.$ 42.11, $p<.001$, Squared Partial Correlation Coefficient $=.05]$. The slope for hopelessness indicated that lower hopelessness was related to better pain management.

\section{Relationship between Proximal and Distal Pain Outcomes}

The test of delta path $(\delta)$ involved using the pain management composite score as the independent variable and QOL composite score as the dependent variable. This path was significant SHARP $\left[X^{2}(1, N=888)=54.96, p<.001\right.$, Squared Partial Correlation Coefficient $=$ .06], which indicates that pain management was a significant predictor of QOL. The slope for pain management showed that worse pain management scores were associated with lower QOL.

\section{DISCUSSION}

This study provides evidence of racial disparities in pain management of primary care patients with chronic nonmalignant pain who were using chronic opioid therapy in that African Americans reported worse pain management and lower QOL than Caucasians, and provides support for the conceptual model of racial disparities in pain management. The data support the link between race and perceived discrimination. African Americans reported more perceived discrimination than Caucasians. This is the first study to report a relationship between perceived discrimination and hopelessness in primary care patients with chronic nonmalignant pain. Higher perceived discrimination was associated with higher hopelessness. This study is also the first to report a relationship between hopelessness and pain management. Lower hopelessness was related to better pain management. Finally, as shown in previous studies in other populations, the findings support the relationship between pain management and QOL in that worse pain management was associated with lower QOL.

One of the major findings of this study is that there are racial disparities in pain management of primary care patients with chronic nonmalignant pain. African Americans reported significantly worse pain management scores than Caucasians. These relationships were significant in analyses that controlled for age, income, education, and disability. This finding supports the only previous study of primary care patients with chronic nonmalignant pain, wherein Chen and colleagues found that African Americans with chronic nonmalignant pain also 
reported worse pain management than Caucasians (Chen, et al., 2005). Similar findings have been reported by other investigators in other pain patient populations including cancer (Bernabei et al., 1998; Cleeland, Gonin, Baez, Loehrer, \& Pandya, 1997; Cleeland et al., 1994) and postoperative patients (Karpman, Del Mar, \& Bay, 1997; Todd, Deaton, D'Adamo, \& Goe, 2000; Todd, Samaroo, \& Hoffman, 1993). Several patient-related factors have been suggested such as attitudinal barriers (Ng, Dimsdale, Rollnik, \& Shapiro, 1996; Ward \& Hernandez, 1994) language barriers, (McDonald, 1994; Todd, et al., 1993) and finances (Rust et al., 2004; TamayoSarver et al., 2003) as explanations for racial disparities for pain management in the United States. Despite the important contributions from these studies, at least three gaps remain: (1) as a body of literature, the results of these studies is inconsistent and limits our conclusions about the findings; (2) none of these factors have been empirically and systematically tested; and (3) majority of these studies did not examine possible psychological factors that explain the disparities in pain management.

The second major finding of this study is that our data supported an empirically and systematically tested model that implicated perceived discrimination and hopelessness as explanatory factors for the racial disparities found in this sample. Regarding perceived discrimination, healthcare researchers have established that perceived discrimination has adverse effects on health outcomes (Kessler, Mickelson, \& Williams, 1999; Schulz et al., 2006). They have also found racial disparities in the negative impact of perceived discrimination (Lee, Ayers, \& Kronenfeld, 2009; Lewis, et al., 2009). For example, African Americans who reported perceived discrimination also had higher diastolic blood pressure than their Caucasian counterparts (Lewis, et al., 2009). The mechanism of action of perceived discrimination on the racial disparities in pain management as proposed in this study was through its relationship to hopelessness. Investigators have found that hopelessness has negative effects on health outcomes and that African Americans are more likely to experience the adverse health consequences of hopelessness than Caucasians (Anda, et al., 1993; Everson et al., 1996; Fiscella \& Franks, 1997). Given findings from this body of literature, primary care providers caring for these patients need to be aware that African Americans reporting everyday perceived discrimination may also have a hopeless outlook in life, which may negatively affect their pain management. Assessing and addressing perceived discrimination and feelings of hopelessness during clinical encounters may be important firsts step to help ameliorate the adverse effects of both factors on pain outcomes.

This conceptual model of racial disparities in pain management could be viewed as a "blaming the victim" model. That is, one could view the model as blaming African Americans for perceiving discrimination or having feelings of hopelessness that could possibly lead to poor pain management. We would argue, however, that in this racial disparities model, individuals are not blamed for perceiving discrimination and having feelings of hopelessness. Instead, the blame is placed on the sociopolitical and cultural systems that perpetrated and condoned racism and discrimination, and created an environment that is psychologically toxic to African Americans. African Americans' world view is, for the most part, through the lenses of racism and discrimination they experienced and over which they had no control. Thus, the society in which this kind of negative experience is possible for only certain members of the population and not others is culpable. For example, one scholar has written that genetics, environmental factors, and the socioeconomic status shape the future of an individual from the moment of birth and that people are "not free to be other than what they are" instead, "they are reflections of their genetics, and the social and economic environment they inhabit"(Dougherty, 1993, p. 114). The contributions of genetics, sociocultural and economic environment as explanatory factors for the 


\section{Racial Disparities in Pain Management in Primary Care - Ezenwa, et al.}

racial disparities in pain management in this population will be an invaluable addition to this body of literature.

Since pain management involves patient, provider, and healthcare system interactions, there are patient-related, provider-related, patient-provider-related, and healthcare systems factors that could explain racial disparities in pain management. For example, findings on patient-provider racial concordance and poor patient-provider communication as explanatory factors for racial disparities in pain management will be invaluable in designing patient-provider educational pain management interventions. Examining these factors is outside the scope of the current study, but they need to be examined in future studies.

An alternative model for racial disparities in pain management may be suggested. For example, one may argue that African Americans who experienced worse pain management may also report having feelings of hopelessness compared to Caucasians. That is, poor pain management may precede hopelessness rather than the other way round as suggested by the current model. This alternative model is plausible because hopelessness has been recognized as a psychological response to a physical illness (Dunn, 2005). Thus, it is logical to state that African Americans who report experiencing worse pain management may subsequently report having feelings of hopelessness. Future research could examine other alternative models, and psychological mediators of the relationship between perceived discrimination and pain management disparities such as anger, hostility, and especially depression. A group of investigators found that $66 \%$ of primary care patients with chronic nonmalignant pain also reported major depression (Arnow et al., 2006).

Our finding that African Americans reported lower QOL than Caucasians is also important. Similar findings have been reported by others who found racial disparities in QOL in patients with chronic nonmalignant pain (Ibrahim, Burant, Siminoff, Stoller, \& Kwoh, 2002). Pain researchers have found that African Americans with chronic nonmalignant pain reported poorer QOL than their Caucasian counterparts (Green, Baker, Smith, \& Sato, 2003; Jordan, Lumley, \& Leisen, 1998). In cancer patients, it has been reported that African Americans reported poorer QOL than Caucasians (Rao, Debb, Blitz, Choi, \& Cella, 2008).

Further, worse pain management was related to lower quality of life. A similar finding has been noted in patients with chronic pelvic pain syndrome (Tripp, Curtis Nickel, Landis, Wang, \& Knauss, 2004). Taken together, this body of literature suggests that in patients with chronic nonmalignant pain, there are racial disparities in QOL wherein African Americans fair worse. It behooves primary care providers who encounter these patients to routinely assess their QOL and suggest coping strategies for them.

Some limitations of a secondary data analysis detract from this study. Although the relationships proposed in the conceptual model of racial disparities in pain management were supported, one needs to be cautious about claiming that these relationships were causal due to the correlational nature of the study. For example, we could not claim that the experience of perceived discrimination caused the feeling of hopelessness. In addition, because of the crosssectional and correlational nature of the study, other alternative directions of the relationships among concepts are possible. To overcome this limitation in the future, it is necessary to replicate this study using a prospective longitudinal design. The complete model needs to be tested again in patients with chronic nonmalignant pain. Another limitation of this study is that patients were recruited from a single state where the ethnic origins of the Caucasians is mostly made up of Germans, Norwegians, and Eastern Europeans who as a group may have a stoic world view. They may respond differently to the perceived discrimination questionnaire than

Journal of Health Disparities Research and Practice, Volume 5, Issue 3, Fall 2012 
other Caucasians. The same argument is also true of the African American group, which could have included patients from Africa, second generation Africans in the United States, and Caribbeans. An examination of the intra-ethnic differences in response to perceived discrimination would have been invaluable for further interpretation of our findings, but one that is outside the scope of this study, and will be examined in a future study.

Our findings have some policy and research implications. As indicated in the 2011 Institute of Medicine report on Relieving Pain in America, nurses and physicians lack systematic training about the barriers to pain treatment, especially in the primary care settings (Institute of Medicine, 2011) Policymakers, should advocate for increased funding for pain research including research that focus on developing patient-centered pain management interventions for patients and culturally-sensitive educational interventions for providers. Furthermore, patientprovider variables, such as racial concordance, communication skill, and mutual trust should be examined in future studies to ascertain the moderating effect of patient-provider interaction on racial disparities in pain management in primary care settings.

\section{CONCLUSION}

In conclusion, this is the first study to examine an explanatory model for the racial disparities in pain management of primary care patients with chronic nonmalignant pain. Perceived discrimination and hopelessness were implicated as explanatory factors for the disparities. Further research is needed to replicate this study using a prospective longitudinal design. These results were obtained after controlling for several demographic and clinical variables that previous research has shown to be confounding variables. Therefore, the findings are interpreted with high confidence.

\section{ACKNOWLEDGEMENTS}

Funding Support: The Funding for this work was made possible by the National Institute of Nursing Research-National Research Service Award (NINR-NRSA) grant: 1F31NR010820 (Principal Investigation: Miriam O. Ezenwa, PhD, RN) and R01DAO13686 (Principal Investigator: Michael Fleming, MD, MPH).

The first author thanks Sandra E. Ward, PhD, RN, FAAN, the Chair of her Dissertation Committee and Ronald C. Serlin, PhD, the Secondary Advisor for their conceptual contributions in their respective substantive areas. The first author also thanks Diana J. Wilkie, PhD, RN, FAAN, her research Faculty Mentor at the University of Illinois at Chicago and Patrick J. McGrath, OC, PhD, FRSC, FCAHS for their contribution with manuscript revisions.

\section{REFERENCES}

Anda, R., Williamson, D., Jones, D., Macera, C., Eaker, E., Glassman, A., \& Marks, J. (1993). Depressed affect, hopelessness, and the risk of ischemic heart disease in a cohort of U.S. adults. Epidemiology, 4(4), 285-294.

Arnow, B. A., Hunkeler, E. M., Blasey, C. M., Lee, J., Constantino, M. J., Fireman, B., . . . Hayward, C. (2006). Comorbid depression, chronic pain, and disability in primary care. $\begin{array}{lllll}\text { Psychosom } \quad \text { Med, 68(2), 262-268. doi: 68/2/262 [pii] } & \end{array}$ 10.1097/01.psy.0000204851.15499.fc

Barnes, L. L., Mendes De Leon, C. F., Wilson, R. S., Bienias, J. L., Bennett, D. A., \& Evans, D. A. (2004). Racial differences in perceived discrimination in a community population of older blacks and whites. J Aging Health, 16(3), 315-337. 
Bernabei, R., Bernabei, R., Gambassi, G., Lapane, K., Landi, F., Gatsonis, C., . . . Mor, V. (1998). Management of pain in elderly patients with cancer. JAMA: Journal of the American Medical Association, 279(23), 1877.

Brazier, J. E., Harper, R., Jones, N. M., O'Cathain, A., Thomas, K. J., Usherwood, T., \& Westlake, L. (1992). Validating the SF-36 health survey questionnaire: new outcome measure for primary care. Bmj, 305(6846), 160-164.

Chen, I., Kurz, J., Pasanen, M., Faselis, C., Panda, M., Staton, L. J., . . Cykert, S. (2005). Racial differences in opioid use for chronic nonmalignant pain. J Gen Intern Med, 20(7), 593598.

Cintron, A., \& Morrison, R. S. (2006). Pain and ethnicity in the United States: A systematic review. J Palliat Med, 9(6), 1454-1473.

Cleeland, C. S., Gonin, R., Baez, L., Loehrer, P., \& Pandya, K. J. (1997). Pain and treatment of pain in minority patients with cancer. The Eastern Cooperative Oncology Group Minority Outpatient Pain Study. Ann Intern Med, 127(9), 813-816.

Cleeland, C. S., Gonin, R., Hatfield, A. K., Edmonson, J. H., Blum, R. H., Stewart, J. A., \& Pandya, K. J. (1994). Pain and its treatment in outpatients with metastatic cancer. $N$ Engl J Med, 330(9), 592-596.

Cleeland, C. S., \& Ryan, K. M. (1994). Pain assessment: global use of the Brief Pain Inventory. Ann Acad Med Singapore, 23(2), 129-138.

Dillie, K. S., Fleming, M. F., Mundt, M. P., \& French, M. T. (2008). Quality of life associated with daily opioid therapy in a primary care chronic pain sample. J Am Board Fam Med, 21(2), 108-117.

Dougherty, C. J. (1993). Bad faith and victim-blaming: the limits of health promotion. Health Care Anal, 1(2), 111-119.

Dunn, S. L. (2005). Hopelessness as a response to physical illness. J Nurs Scholarsh, 37(2), 148154.

Everson, S. A., Goldberg, D. E., Kaplan, G. A., Cohen, R. D., Pukkala, E., Tuomilehto, J., \& Salonen, J. T. (1996). Hopelessness and risk of mortality and incidence of myocardial infarction and cancer. Psychosom Med, 58(2), 113-121.

Everson, S. A., Kaplan, G. A., Goldberg, D. E., Salonen, R., \& Salonen, J. T. (1997). Hopelessness and 4-year progression of carotid atherosclerosis. The Kuopio Ischemic Heart Disease Risk Factor Study. Arterioscler Thromb Vasc Biol, 17(8), 1490-1495.

Ezenwa, M. O., Ameringer, S., Ward, S. E., \& Serlin, R. C. (2006). Racial and ethnic disparities in pain management in the United States. Journal of Nursing Scholarship, 38(3), 225233.

Feagin, J. R., \& Feagin, J. R. (1991). THE CONTINUING SIGNIFICANCE OF RACE: ANTIBLACK DISCRIMINATION IN PUBLIC PLACES. American Sociological Review, 56(1), 101.

Finch, B. K., Kolody, B., \& Vega, W. A. (2000). Perceived discrimination and depression among Mexican-origin adults in California. J Health Soc Behav, 41(3), 295-313.

Fiscella, K., \& Franks, P. (1997). Does psychological distress contribute to racial and socioeconomic disparities in mortality? Soc Sci Med, 45(12), 1805-1809.

Fleming, M. F., Balousek, S. L., Klessig, C. L., Mundt, M. P., \& Brown, D. D. (2007). Substance use disorders in a primary care sample receiving daily opioid therapy. J Pain, 8(7), 573582. 
Fredheim, O. M., Kaasa, S., Fayers, P., Saltnes, T., Jordhoy, M., \& Borchgrevink, P. C. (2008). Chronic non-malignant pain patients report as poor health-related quality of life as palliative cancer patients. Acta Anaesthesiol Scand, 52(1), 143-148.

Goertz, C. M. H. (1994). Measuring functional health status in the chiropractic office using selfreport questionnaires. Topics in Clinical Chiropractic, 1(1), 51-59.

Green, C. R., Baker, T. A., Smith, E. M., \& Sato, Y. (2003). The effect of race in older adults presenting for chronic pain management: a comparative study of black and white Americans. J Pain, 4(2), 82-90.

Ho, M.-J., \& LaFleur, J. (2004). The treatment outcomes of pain survey (TOPS): a clinical monitoring and outcomes instrument for chronic pain practice and research. $J$ Pain Palliat Care Pharmacother, 18(2), 49-59.

Ibrahim, S. A., Burant, C. J., Siminoff, L. A., Stoller, E. P., \& Kwoh, C. K. (2002). Self-assessed global quality of life: a comparison between African-American and white older patients with arthritis. J Clin Epidemiol, 55(5), 512-517.

Institute of Medicine. (2011). Relieving Pain in America: A Blueprint for transforming prevention, care, education, and research: Institute of Medicine.

Jordan, M. S., Lumley, M. A., \& Leisen, J. C. (1998). The relationships of cognitive coping and pain control beliefs to pain and adjustment among African-American and Caucasian women with rheumatoid arthritis. Arthritis Care Res, 11(2), 80-88.

Karpman, R. R., Del Mar, N., \& Bay, C. (1997). Analgesia for emergency centers' orthopaedic patients: does an ethnic bias exist? Clin Orthop Relat Res(334), 270-275.

Kessler, R. C., Mickelson, K. D., \& Williams, D. R. (1999). The prevalence, distribution, and mental health correlates of perceived discrimination in the United States. J Health Soc Behav, 40(3), 208-230.

Krause, M. R., Serlin, R. C., Ward, S. E., Rony, R. Y., Ezenwa, M. O., \& Naab, F. (2010). Testing mediation in nursing research: beyond Baron and Kenny. Nurs Res, 59(4), 288294. doi: 10.1097/NNR.0b013e3181dd26b3

Krieger, N. (1990). Racial and gender discrimination: risk factors for high blood pressure? Soc Sci Med, 30(12), 1273-1281.

Lee, C., Ayers, S. L., \& Kronenfeld, J. J. (2009). The association between perceived provider discrimination, healthcare utilization and health status in racial and ethnic minorities. Ethn Dis, 19(3), 330-337.

Lewis, T. T., Barnes, L. L., Bienias, J. L., Lackland, D. T., Evans, D. A., \& Mendes de Leon, C. F. (2009). Perceived discrimination and blood pressure in older African American and white adults. J Gerontol A Biol Sci Med Sci, 64(9), 1002-1008.

MacKinnon, D. P., Lockwood, C. M., Hoffman, J. M., West, S. G., \& Sheets, V. (2002). A comparison of methods to test mediation and other intervening variable effects. Psychol Methods, 7(1), 83-104.

Marascuilo, L. A., \& Levin, J. R. (1983). Multivariate statistics in the social sciences: A researcher's guide. New York McGraw-Hill.

McDonald, D. D. (1994). Gender and ethnic stereotyping and narcotic analgesic administration. Res Nurs Health, 17(1), 45-49.

Meghani, S. H., Byun, E., \& Gallagher, R. M. (2012). Time to take stock: a meta-analysis and systematic review of analgesic treatment disparities for pain in the United States. Pain Med, 13(2), 150-174. doi: 10.1111/j.1526-4637.2011.01310.x 
Ng, B., Dimsdale, J. E., Rollnik, J. D., \& Shapiro, H. (1996). The effect of ethnicity on prescriptions for patient-controlled analgesia for post-operative pain. Pain, 66(1), 9-12.

Rao, D., Debb, S., Blitz, D., Choi, S. W., \& Cella, D. (2008). Racial/Ethnic differences in the health-related quality of life of cancer patients. J Pain Symptom Manage, 36(5), 488-496.

Ren, X. S., Amick, B. C., \& Williams, D. R. (1999). Racial/ethnic disparities in health: the interplay between discrimination and socioeconomic status. Ethn Dis, 9(2), 151-165.

Rusch, N., Corrigan, P. W., Powell, K., Rajah, A., Olschewski, M., Wilkniss, S., \& Batia, K. (2009). A stress-coping model of mental illness stigma: II. Emotional stress responses, coping behavior and outcome. Schizophrenia Research, 110(1-3), 65-71. doi: S09209964(09)00035-8 [pii] 10.1016/j.schres.2009.01.005

Rust, G., Nembhard, W. N., Nichols, M., Omole, F., Minor, P., Barosso, G., \& Mayberry, R. (2004). Racial and ethnic disparities in the provision of epidural analgesia to Georgia Medicaid beneficiaries during labor and delivery. Am J Obstet Gynecol, 191(2), 456-462.

Schouten, H. J. (2000). Combined evidence from multiple outcomes in a clinical trial. J Clin Epidemiol, 53(11), 1137-1144. doi: S0895-4356(00)00238-9 [pii]

Schulz, A. J., Gravlee, C. C., Williams, D. R., Israel, B. A., Mentz, G., \& Rowe, Z. (2006). Discrimination, symptoms of depression, and self-rated health among african american women in detroit: results from a longitudinal analysis. Am J Public Health, 96(7), 12651270.

Serlin, R. C., \& Harwell, M. R. (2004). More powerful tests of predictor subsets in regression analysis under nonnormality. Psychol Methods, 9(4), 492-509. doi: 2004-21445-007 [pii] 10.1037/1082-989X.9.4.492

Tamayo-Sarver, J. H., Dawson, N. V., Hinze, S. W., Cydulka, R. K., Wigton, R. S., Albert, J. M., . . . Baker, D. W. (2003). The effect of race/ethnicity and desirable social characteristics on physicians' decisions to prescribe opioid analgesics. Acad Emerg Med, 10(11), 1239-1248.

Tan, G., Jensen, M. P., Thornby, J. I., \& Shanti, B. F. (2004). Validation of the Brief Pain Inventory for chronic nonmalignant pain. J Pain, 5(2), 133-137.

Todd, K. H., Deaton, C., D'Adamo, A. P., \& Goe, L. (2000). Ethnicity and analgesic practice. Ann Emerg Med, 35(1), 11-16.

Todd, K. H., Samaroo, N., \& Hoffman, J. R. (1993). Ethnicity as a risk factor for inadequate emergency department analgesia. Jama, 269(12), 1537-1539.

Tripp, D. A., Curtis Nickel, J., Landis, J. R., Wang, Y. L., \& Knauss, J. S. (2004). Predictors of quality of life and pain in chronic prostatitis/chronic pelvic pain syndrome: findings from the National Institutes of Health Chronic Prostatitis Cohort Study. BJU Int, 94(9), 12791282.

Tuzun, E. H. (2007). Quality of life in chronic musculoskeletal pain. Best Pract Res Clin Rheumatol, 21(3), 567-579.

Ward, S. E., \& Hernandez, L. (1994). Patient-related barriers to management of cancer pain in Puerto Rico. Pain, 58(2), 233-238.

Williams, D. R., Yu, Y., Jackson, J. S., \& Anderson, N. B. (1997). Racial Differences in Physical and Mental Health: Socio-economic Status, Stress and Discrimination. Health and socioeconomic position, 2(3), 335-351.

Willoughby, S. G., Hailey, B. J., \& Wheeler, L. C. (1999). Pain Patient Profile: a scale to measure psychological distress. Arch Phys Med Rehabil, 80(10), 1300-1302. 


\section{CONTACT INFORMATION}

Miriam O. Ezenwa, PhD, RN

Assistant Professor, Sickle Cell Scholar, and Mayday Fellow

College of Nursing

University of Illinois at Chicago

845 South Damen Avenue, Room 636 (MC/802)

Chicago, IL 60612-7350

Phone: 312-996-5071

E-mail: $\underline{\text { moezenwa@uic.edu }}$

Michael F. Fleming, MD, MPH

Professor and Vice Chair for Research and Faculty Development

Department of Family and Community Medicine

Northwestern University

Email: $\underline{\text { m-fleming@northwestern.edu }}$ 